Supporting Information

\title{
High-Quality Violet- to Red-emitting ZnSe/CdSe Core/shell Nanocrystals
}

Xinhua Zhong, Renguo Xie, Ying Zhang, Thomas Basché, and Wolfgang Knoll
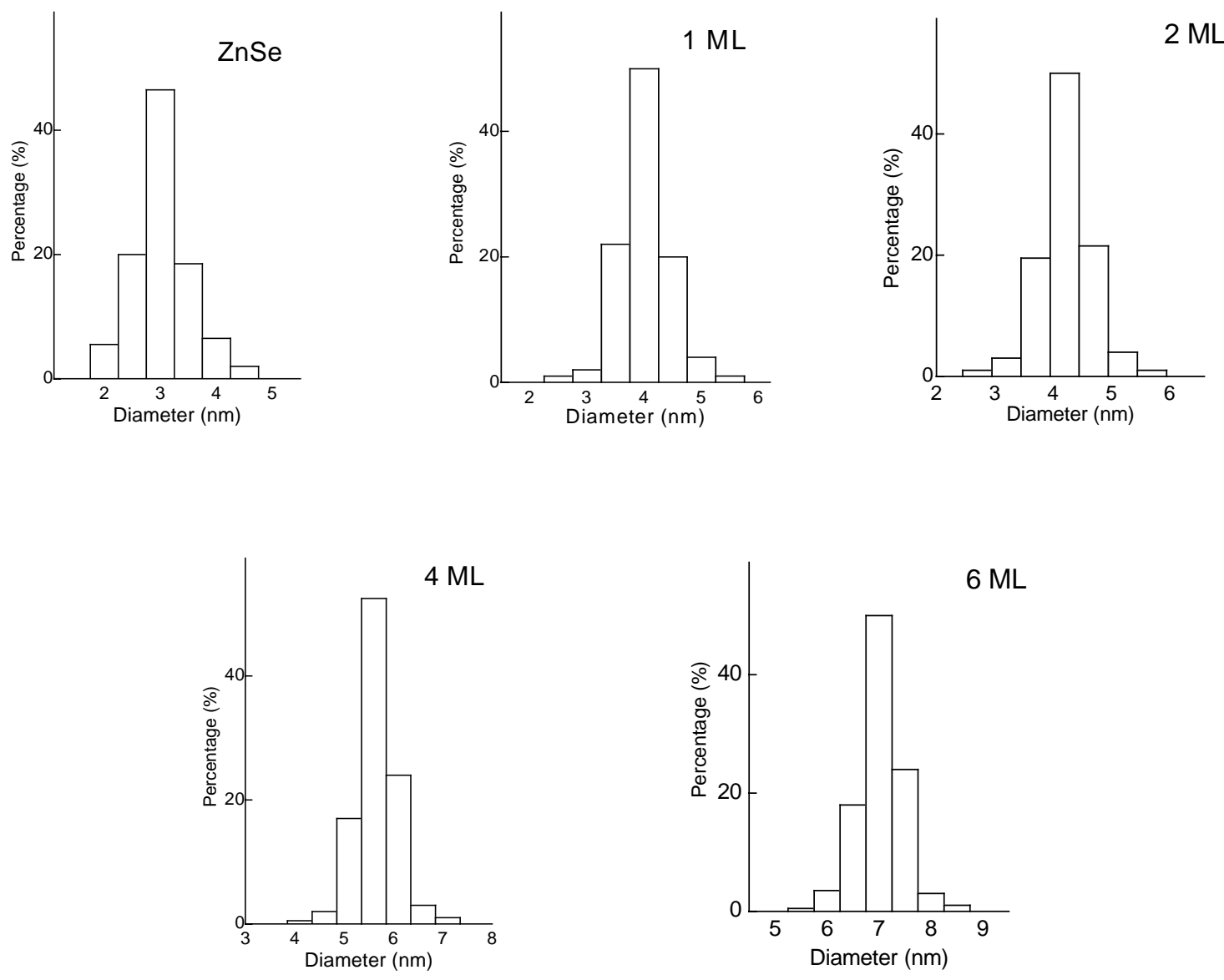

Figure 1s. Size distribution histograms of ZnSe core nanocrystals and ZnSe/CdSe core/shell nanocrystals with 1, 2, 4, 6 monolayer of CdSe shells, respectively. 